\title{
Plano de imanência e univocidade do ser em Deleuze
}

Jairo Dias Carvalho

jairodc_8@hotmail.com

Universidade Federal de Uberlândia, Uberlândia, Minas Gerais, Brasil

resumo 0 texto pretende mostrar que, apesar de Deleuze dizer que a univocidade possui três grandes momentos na história da filosofia, Duns Scoto, Spinoza e Nietzsche, sua filosofia mesma constitui um momento contemporâneo nesta história. Será a ideia de plano de imanência a resposta propriamente deleuziana ao problema da oposição entre a analogia de proporção e a univocidade do ser na história da filosofia.

palavras-chave plano de imanência; univocidade do ser; Deleuze; multiplicidade virtual; ontologia; analogia de proporção.

\section{Introdução}

A filosofia de Deleuze se apresenta como uma filosofia da imanência. Isto significa a concepção de que será a articulação intrínseca do múltiplo por si mesmo que produzirá sentido sem que haja referência a um termo exterior a esta articulação como tal. Uma filosofia da imanência é uma filosofia que pensa a articulação interna de termos em relação sem remissão a um termo fora dessa articulação que portaria o sentido da relação: o sentido é dado pela própria relação.

Esta filosofia da imanência de Deleuze é constituída a partir da crítica às idéias de eminência e transcendência. A transcendência é uma figura da eminência, cuja gênese é o uso da analogia de proporção, que instaura um termo tomado como tipo para a atribuição de sentido e de valor aos outros termos em relação. Os termos em relação somente ganham valor e 
sentido a partir da participação proporcional ao termo tomado como tipo. Assim, na analogia de proporção há sempre um termo que possui mais valor e sentido que outros. Julgam-se os outros termos em relação a partir desse termo típico. A idéia de transcendência é a constituição de um termo ou realidade radicalmente separada aos termos em relação e que possui por isso um sentido superior àquele da realidade da qual é separada. A referência de significação dos termos de uma multiplicidade a um termo desta multiplicidade é chamada "analogia de proporção". Em uma analogia de proporção a relação de um termo a outro tomado como tipo não é a mesma relação de outro termo a este tomado como tipo. Sem uma relação qualquer que seja de um termo ou dos termos a um termo tomado como tipo não há significação. A formulação de Aristóteles de que o ser se diz em vários sentidos implica o uso da analogia de proporção. O ser se diz em muitos sentidos porque ancorado em uma analogia de proporção que referencia os muitos sentidos em um sentido tomado como tipo, a substância. Toda e qualquer eminência implica o uso da analogia de proporção, ou seja, a constituição de um termo que porta o sentido mais do que outros. A analogia implica participação dos sentidos do ser a um sentido primeiro. A formulação da analogia de proporção é feita da seguinte maneira: “Assim como A, B também se relaciona a X, mas diferente do modo como A se relaciona a X”. Já a univocidade significa a atribuição de um mesmo nome a diversos termos segundo uma razão ou uma significação absoluta. Ela significa a unidade de sentido na atribuição desses sentidos a vários termos. É em torno da crítica à noção de analogia que aparecerá o pensamento da imanência em Deleuze.

Haveria três eixos filosóficos em jogo em torno do debate entre a analogia e univocidade do ser: 1 - as filosofias da pluralidade dos sentidos do ser orientados a um termo tomado como unidade de significação, ou seja, a remissão da unidade a um termo interno ao múltiplo; 2- as filosofias que pensam a unidade a partir de um termo externo ao múltiplo, este termo sendo ou produtor ou modelo; 3- as filosofias da diferença ou das multiplicidades, que concebem que é na articulação do múltiplo por si e em si que aparecem o sentido e a significação. Há o campo que pensa a multiplicidade a partir da unidade interna a esta multiplicidade; o campo que pensa a multiplicidade a partir da unidade externa a esta multiplicidade; e aquele que pensa a multiplicidade nela 
mesma sem referi-la a uma unidade. Será este último campo que desenvolveremos a seguir.

\section{Os momentos da univocidade}

Deleuze diz que a univocidade possui três grandes momentos na história da filosofia, Scotus, Spinoza e Nietzsche (DELEUZE, 1997, p. 52-61). Será a idéia de plano de imanência a resposta propriamente deleuziana ao problema da oposição entre a analogia de proporção e a univocidade do ser na história da filosofia. A concepção deleuziana da univocidade concebe uma lógica do múltiplo pelo múltiplo. Este problema de uma lógica própria ao múltiplo perpassa a obra de Deleuze como um todo. Sua apropriação da história da filosofia visa libertar o múltiplo da eminência e da exterioridade a partir da crítica ao uso da analogia de proporção.

A filosofia de Duns Scotus esposa a tese da univocidade do ser. Sua filosofia coloca a questão da inconsistência do uso da analogia de proporção que acarreta a eminência. Sejam dois termos em relação e em comparação, na analogia de proporção um dos termos será tomado como tipo ou critério para a atribuição do sentido do outro termo em relação. Scotus diz que uma relação de proporção exige um termo médio que seja comum aos dois em relação. É aí que concebe o conceito de ser como unívoco em suas determinações mais gerais e é esse conceito neutro que serviria como termo médio ao uso da analogia de proporção. A univocidade do ser significa que, em suas determinações mais gerais, o ser é dito de todo ente, o que acarreta a não existência de uma forma ontologicamente superior de ser em suas determinações mais gerais. Há distinção entre os seres, mas esta não é ontológica. Há diferenças entre os seres, mas esta diferença não acarreta superioridade, pelo menos nas determinações mais gerais. Scotus, ao atacar a ideia de eminência, afirma a necessidade de um termo médio, para que haja uma comparação analógica que permita a atribuição de superioridade de um termo em relação a outro.

Deleuze aceita a crítica scotista à eminência e à analogia, mas concorda apenas em parte com a solução do problema. Em Scotus, a univocidade se refere ao conceito de ser tomado como neutro. $\mathrm{Na}$ sua indeter- 


\section{8}

minação mais geral o conceito de ser se diz em sentido unívoco. Duns Scotus postula a existência de um termo médio que serve de referência à atribuição de significação: para que haja o funcionamento de uma analogia de proporção, os termos em relação devem ser remetidos a um termo médio tomado como neutro (o conceito de ser como aliquid).

Em Duns Scotus o ser se diz no mesmo sentido de tudo o que é, mas não sob a mesma modalidade (que são o finito e o infinito). Ao lado da tese da univocidade do ser, Scotus utiliza um de seus conceitos mais originais, segundo Deleuze (DELEUZE, 1968, p. 54), que vem completar àquele da univocidade: a ideia de distinção formal. Ela significa a apreensão de qüididades distintas que pertencem a um sujeito. Não se trata de exprimir uma mesma realidade sob dois aspectos que poderiam existir à parte em outros sujeitos, nem de exprimir uma mesma coisa por diversos graus de abstração, nem de exprimir alguma coisa analogicamente por relação a outras realidades, mas da apreensão de formas atualmente distintas, que como tais, compõem um só e mesmo sujeito, ou são inseparáveis nele. Para Deleuze (DELEUZE, 1968, p. 55-57), a distinção formal é uma espécie de distinção real, porque exprime as diferentes camadas de realidade que formam ou constituem um ser. Trata-se de distinguir a composição de um ser em qüididades realmente distintas que se coordenam e o compõem. E essas qüididades distintas se comunicam por um terceiro termo ao qual são idênticas ou se referem. Os atributos de Deus são formalmente distintos, mas ontologicamente idênticos. Como é uma modalidade do ser (e não um atributo), a infinitude pode ser comum a razões formais quiditativamente irredutíveis e lhes conferir identidade, sem suprimir sua distinção na formalidade. Deus é absolutamente Um, mas possuidor de qüididades distintas.

Para Deleuze (DELEUZE, 1997, p. 55) quando consideramos o conceito de ser não mais em sua natureza enquanto ser, mas em suas modalidades individuantes, ele cessa de ser unívoco. E isso ocorre por que Scotus quer evitar o panteísmo. A perspectiva teológica o força a conceber o ser unívoco como um conceito neutralizado, indiferente. Há ainda uma hierarquia e uma distribuição do sentido. Mas Deleuze diz que a distribuição e a hierarquia possuem duas acepções diferentes, sem conciliação possível. É preciso distinguir um tipo de distribuição que implica uma partilha do distribuído e que procede por determinações fixas e 
proporcionais de outro tipo de distribuição que é chamada de nomádica. Nessa segunda não se trata de partilhar uma coisa que seria distribuída, tal um termo tomado como tipo e segundo o qual o sentido é atribuído e distribuído em referência a esse termo. Trata-se de uma distribuição ou repartição daqueles que se distribuem em um espaço aberto ou sem limites precisos. Trata-se de preencher um espaço, ocupá-lo, e não de partilhar o espaço. O sentido não é "distribuído" a partir de uma unidade focal de significação, mas se auto-distribui na relação entre os termos. A distribuição do sentido do ser em Scotus parece seguir esse segundo tipo de distribuição. Parece, também, que Deleuze acredita que um conceito de ser unívoco, mas apenas em suas determinações mais gerais, ou se quisermos, em estado indeterminado, só serve em partes à sua filosofia. $\mathrm{O}$ que lhe interessa em Scotus é que sua formulação de um conceito unívoco de ser mesmo neutralizado, no sentido de não atribuição própria a nenhum termo, lhe possibilita a primeira crítica consistente ao problema da analogia de proporção e à idéia de eminência.

Deleuze pensa não no ser que se partilha, mas nas coisas sendo repartidas nele. Não aceita uma hierarquia que mede os seres segundo seus limites e segundo seu grau de proximidade, ou de distanciamento, em relação a um princípio tomado como típico ou eminente. Mas busca uma hierarquia que considera as coisas e os seres do ponto de vista da potência. Busca uma medida envolvente, que seria a mesma para todas as coisas, algo como um plano que envolveria as coisas. Assim, pergunta a Scotus: "Se o ser é unívoco nele mesmo enquanto ser, não é ele análogo quando o tomamos com seus modos intrínsecos ou fatores individuantes? Se ele é igual nele mesmo não é ele desigual em suas modalidades que se encerram nele? Se ele designa uma entidade comum não é para os existentes que não tem realmente nada em comum?” (DELEUZE, 1997, p. 55).

A analogia de proporção em Aristóteles visa negar que o ser seja um gênero comum, porque as diferenças (específicas) também "seriam", e não poderia haver diferenças se elas tivessem a mesma realidade ontológica que aquilo que vêm especificar. Quando Aristóteles afirma que o ser se diz em muitos sentidos, mas relativamente a um termo único, funda um tipo de procedimento que podemos chamar de unidade de convergência - de consecução - a unidade de proveniência, ou o que a tradição chamou de analogia de atribuição - ou de proporção - ou ainda, 
contemporaneamente, de unidade focal de significação, que é a instância que unifica as significações múltiplas do ser. A pluralidade de significações, o ser que não se diz de maneira unívoca, é referida a um sentido tomado como primeiro. Esse termo tomado como primeiro é a unidade de significação por convergência ou unidade focal de significação. Uma das significações do ser é primeira e todas as outras implicam em sua definição uma relação a essa significação primordial. Não se trata de uma igualdade de relações (o que seria uma analogia em sentido próprio), mas o fato de que as relações a cada vez diferentes comportam um termo idêntico ao qual se referem. Em Aristóteles, as categorias se relacionam ao primeiro (substância), não somente de maneira diferente, mas segundo uma diversidade que é regulada sobre a maneira de ser de cada categoria, sobre suas maneiras desiguais de se relacionarem à substância. A analogia de atribuição exprime, assim, a participação gradual dos termos derivados a um termo primeiro, participação gradual na medida em que ela é proporcional ao mérito de cada um dos participantes.

Em Duns Scotus, se o ser é unívoco, as diferenças (individuantes) não são, em um sentido particular, mas se elas não são, é porque dependem no ser unívoco de um não ser sem negação. Aparece na univocidade scotista a idéia de que as diferenças não são o ser, mas possuem ser por derivação. $\mathrm{O}$ ser em Scotus é pensado como unívoco, mas esse é neutro, indiferente, ou ele só é unívoco em suas determinações mais gerais, ou na sua indeterminação.

Deleuze usa Spinoza para criticar Scotus, já que para ele "Spinoza opera um progresso considerável. No lugar de pensar o ser unívoco como neutro ou indiferente, ele o faz objeto de uma afirmação pura. O ser unívoco se confunde com a substância única, universal e infinita: ele é posto como Deus sive Natura" (DELEUZE, 1997, p.58). A substância se diz univocamente de tudo o que é dito ser, mas mediada pelo atributo. Nem tudo é substância, mas tudo o que é dito ser, ou é substância, ou está, ou é, pela substância. O atributo permite a univocidade, porque é uma forma comum à substância e aos modos. Os modos são na substância pelos atributos e participam ontologicamente da substância pelo atributo, participam da essência da substância, mas são diferentes da substância. Como diz Deleuze, “os atributos são absolutamente comuns à substância e aos modos, se bem que a substância e os modos não tenham a mesma essência” (DELEUZE, 1997, p.58). Os atributos explicam e 
constituem a substância e implicam os modos. Os modos são quanta de realidade das qualidades constituintes da substância, os atributos, e neste sentido são diferentes essencialmente da substância, mas estão nela. Têm algo formalmente da substância, porque implicam atributos que são qualidades constituintes da substância. O ser se diz unívoco, enquanto ou é, ou está na substância. Estar na substância é fazer parte dela, e isso garante que não há forma superior de ser até ou que a diferença não é pensada como eminência.

Façamos um pequeno comentário sobre a filosofia de Giordano Bruno. Deleuze não possui um trabalho de fôlego sobre Bruno por isso o estudamos desenvolvendo um pequeno comentário que ele faz (DELEUZE, 1968, p. 159.) sobre a elaboração acabada do conceito de complicação em Bruno.

Para Bruno, o termo médio não pode ser neutro, mas dizer positivamente de; é assim que a natureza é o termo de referência, e é este termo que é unívoco e se diz de todo ente. Mas diz o ser enquanto natureza naturante (complicatio) e natureza naturada (explicatio). Assim, todo ser ou é natureza complicada ou natureza explicada. Com Giordano Bruno, a univocidade se refere à natureza, que é dita univocamente, mas distinguida em natureza naturante e natureza naturada.

Spinoza introduz um termo comum a esta "dualidade" bruniana, o atributo. $\mathrm{O}$ atributo é a forma comum à substância que explica e constitui e aos modos que implica. É como se Spinoza postulasse um termo médio de ligação entre a natureza naturante e natureza naturada de Bruno. Com Spinoza, a partir da relação substância/ atributo, Deleuze chega à formulação da existência de formas comuns à substância e aos modos, os atributos, permitindo conceber que não há formas superiores de ser. É como se Spinoza exigisse que, se a natureza é o ser, sendo natureza complicada e natureza explicada podendo ser dito de "ente", então, devêssemos conceber um termo comum que se refira tanto à natureza naturante (agora pensada como substância) quanto à natureza naturada (os modos), o atributo. $\mathrm{O}$ atributo é forma comum à substância que explica e constitui, e por isso guarda formalmente suas "propriedades", e aos modos que são implicados nele. A partir disso Deleuze concebe o atributo, como forma comum à substância e aos modos, por que tal concepção permite uma crítica à idéia de eminência. 
Com o conceito de natureza de Bruno e da substância como causa de si em Spinoza vemos aparecer a idéia de uma não-exterioridade radical à natureza nem formas superiores de ser. Não há exterioridade à natureza (imanência) nem formas absolutas de ser (univocidade). Se não há formas superiores de ser nem eminência do tipo, não há um termo interno ou externo ao múltiplo que garanta a unidade de significação do próprio múltiplo. Mesmo assim, Deleuze critica Spinoza.

Deleuze não aceita a substância spinozista como resposta integral ao problema da univocidade, mas se apropria de uma formulação de Spinoza quanto ao problema da univocidade para pensar o problema da não existência de uma superioridade eminente. Há formas diferentes de ser, mas que não são superiores. A diferença modo/ substância é pensada como diferença entre o que é por si, causa de si, e o que é em outro, mas tanto ser causa de si e ser em outro se comunicam em uma forma, em um termo médio, o atributo. O que é causa de si se expressa nos atributos, e o que é em outro (os modos) está implicado nessas mesmas formas constitutivas, os atributos.

Mas o problema é que subsiste em Spinoza uma diferença entre os termos em relação, entre a substância e os modos. E mesmo não sendo uma diferença eminente, Deleuze critica essa posição. Para compreender a crítica de Deleuze a Spinoza é preciso compreender porque, mesmo aceitando a diferença de essência entre substância e modo como não eminente, ainda, assim, ele critica essa diferença. Há uma raridade dos textos na obra de Deleuze que impossibilita a compreensão exaustiva desse problema. O problema é compreender porque mesmo a substância não constituindo seus modos eminentemente, Deleuze não aceita que a substância seja dita por si independentemente dos modos. A univocidade de uma forma comum, que numa face explica e constitui a substância e noutra implica os modos, ou seja, a existência de uma forma comum que pertence de maneira unívoca a um termo que explica e constitui e a outro que implica nos esclarece que não há formas superiores de ser, quanto a isso Deleuze pode concordar. Mas a ideia de uma não-superioridade das formas de ser não implica a não distinção de essência, o que Deleuze também aceitaria, porque senão teríamos a unidade absoluta, mesmo assim, parece que finalmente o modo da distinção das essências em Spinoza não agrada a Deleuze. Senão, vejamos: "Será preciso que a 
substância se dissesse ela mesma dos modos e somente dos modos" (DELEUZE, 1997, p.59). Esta é a frase que resume a crítica a Spinoza. A substância se diz dos modos pelos atributos, o que garante a não superioridade das formas de ser, mas isso não significa, segundo Deleuze, a garantia da univocidade do ser ou que o múltiplo seja afirmado.

O ser se diz enquanto atributo, ou é atributo pensado como qualidade constitutiva da substância, ou como quantidade dessa qualidade constitutiva, o modo. A univocidade é garantida pela substância porque o que é, é qualificado e quantificado. Como qualidade ou quantidade de qualidade de uma substância o ser é unívoco, enquanto substância qualificada e enquanto quantidade dessa qualidade constitutiva. O ser se diz em um só e mesmo sentido enquanto é por si ou em outro. Ao exigir que a substância seja dita dos modos acreditamos que Deleuze critica a idéia da substância como sendo causa de si. Mesmo que aceite que a substância é causa de si no mesmo sentido que é causa dos modos, no nosso entender é essa condição de causa de si, ou a idéia de que um termo da relação substância/ modos possa ter o poder de se causar a si, que Deleuze critica. Para nós não há outro modo de se entender a exigência de que a substância deva ser dita dos modos. Não que Deleuze critique a idéia de uma causa sui, tanto que defende a univocidade da causa de si como uma das figuras da univocidade em Spinoza ou dizendo que a noção de causa sui porta o segredo da causa eficiente. Mas o problema de admitir a causa sui é admitir que um dos termos em relação porta mais significação que outros. Talvez Deleuze quisesse exigir de Spinoza que ele dissesse que os modos se causariam a si mesmos no mesmo sentido que a substância causa a si mesma, provocando uma inversão no spinozismo.

A filosofia de Spinoza serve a Deleuze enquanto possibilita a formulação da inexistência de uma forma superior de ser, mas isso no que diz respeito à relação entre substância e atributo, e não na relação entre substância e modos. Com Spinoza, Deleuze diz que os atributos são formalmente distintos, mas ontologicamente um, porque são atributos da substância e a expressam e constituem; logo são como que homogêneos em relação à sua natureza de causa de si, à sua essência infinita e eterna. Formalmente, eles são a substância no sentido de serem constituintes de sua essência, cada um em seu domínio. Se eles são constituintes possuem formalmente suas “propriedades”. Os atributos são unívocos em relação 


\section{4}

à substância, a substância se diz no mesmo sentido que os atributos do ponto de vista da homogeneidade entre ambos e da relação de exprimível e expressão, melhor dizendo, do caráter da inseparabilidade do que se exprime e de sua expressão, o exprimível não existe fora de suas expressões. Mas há uma diferença de essência entre a substância e os modos, os modos sendo diferença, As individuantes quantitativas, graus de potência ou de intensidade. Sendo, assim, pode dizer Deleuze "Faltaria ao spinozismo, para que univocidade se tornasse objeto de afirmação pura, fazer a substância girar em torno dos modos, quer dizer realizar a univocidade como repetição no eterno retorno" (DELEUZE, 1997, p.388).

Para que a substância se dissesse dos modos Deleuze acha necessária a reversão do ponto de vista do pensamento e de suas categorias. É nesse sentido e mesmo nesse momento, no nosso entender, que Deleuze se aproxima de Nietzsche. Ele defende que esta reversão categorial implicaria conceber o ser a partir do devir (DELEUZE, 1997, p.59). O ser se diria do devir, a identidade do diferente e o um do múltiplo. Ser, identidade, unidade seriam segundas em relação a devir, diferença e multiplicidade. Deleuze afirma que, a partir de Nietzsche, não há ser além do devir, assim como o Um além do múltiplo (DELEUZE, 1988, p.27). Inicia-se, então, a justificação - via concepção da univocidade em Nietzsche - de uma lógica do múltiplo pelo múltiplo. É a partir de como compreende o conceito de eterno retorno em Nietzsche que Deleuze formula uma concepção da univocidade que se relaciona à variação, à diferença e ao múltiplo. Para Deleuze o eterno retorno nietzschiano não significa o retorno do idêntico, pois se supõe um mundo onde todas as identidades prévias são abolidas.

O mundo para Nietzsche é um campo de forças, as quais são determinadas internamente na sua variação pela vontade de potência. Trata-se de um dinamismo interno à força que produz diferenças de qualidades e quantidades em um campo ao infinito. A vontade de potência é um elemento interno à força e o que a determina a agir. É a condição de gênese da qualidade e quantidade da força.

É nesse mundo de potências e de forças que Deleuze concebe o eterno retorno como um processo de seleção, onde só as diferenças retornam. O retornar de uma variação é uma repetição do que varia. Para Deleuze, retornar é ser, é o ser do devir ou constituído a partir do devir. 
O eterno retorno não faz revir o mesmo, mas revir constitui o ser mesmo do que devém. O Ser é revir ou a repetição do devir. O que devém revém e aí se constitui o ser. Revir constitui uma identidade, mas segunda em relação ao devir. Devir significa diferir-se e repetir significa a constituição da identidade. A identidade é repetição. Só pode repetirse o que atinge uma forma extrema de potência. O eterno retorno é o processo de constituição do ser porque implica a eterna repetição infinita daquilo que devém, mas somente retorna aquilo que é potente. $\mathrm{O}$ eterno retorno é a univocidade nietzschiana: aquilo que pode ser dito ser é dito ser porque retorna. $\mathrm{O}$ ser como eterno retorno se diz de todos os entes. Mas a univocidade nietzschiana afirma a diferença como tal. Tudo que é diferença, multiplicidade, é dito ser porque se repete. A compreensão deleuziana do eterno retorno é ontológica. O ser é aquilo que revém, que retorna, que se repete. Sem o eterno retorno há variação infinita sem constituição de nada. O eterno retorno é o ser comum a todas as coisas que são desiguais, diferentes e múltiplas. Isso que pode ser dito ser é dito ser porque retorna. O ser tem um só e mesmo sentido para tudo o que pode ser dito ser: é eterno retorno. Há, então, um só nome para o ser como retorno ou repetição do que ele se diz. Mas a questão toda é que mesmo assim há diferenças nesse mundo, porque se é dito ser tudo o que retorna, o conteúdo do que retorna não é unívoco. Sendo ser, é eterno retorno, mas é retorno de algo que sempre é variável em si, logo é retorno do diferente. O eterno retorno se diz de um mundo sem identidade prévia, ele se diz de um mundo das diferenças que se repercutem ao infinito.

Nietzsche concebe o mundo como um mundo de forças, as forças tem um componente interno que é sua condição de gênese e diferenciação, a vontade de potência, princípio de produção das diferenças de qualidade e de quantidade das forças. É em relação a este mundo que vemos operar outro princípio ontológico, o eterno retorno, que significa o eterno repetir-se, assim como a vontade de potência significa a variabilidade infinita. É na junção desses dois movimentos que se origina o "ser". Assim, o eterno retorno se elabora e dá origem ao ser, nesse fundo das forças, que é a natureza original pensada como caos.

O eterno retorno não é uma lei exterior imposta ao caos, mas a identidade interna do mundo e do caos. Naquilo que é variação pura há 
outro princípio operante que é a repetição. O repetir-se e o variar-se são dois princípios ontológicos do caos. O Caos aqui é entendido como variabilidade infinita. Podemos falar então de revir-outro, revir-o-mesmo, devir-outro, devir-o mesmo:

O eterno retorno é bem o Semelhante, a repetição e a identidade não preexistem ao retorno do que revém. Eles não qualificam de início isto que revém, eles não se confundem absolutamente com seu retorno. Não é o mesmo que revém, não é o semelhante que revém, mas o Mesmo é o revir disto que revém, quer dizer do Diferente, o semelhante é o revir do que revém, quer dizer do Dessemelhante. A repetição no eterno retorno é o mesmo, mas enquanto ele se diz unicamente da diferença e do diferente (DELEUZE, 1997, p.384).

A ideia de devir pode ser pensada a partir do verbo tornar-se. Temos, assim, um tornar-se outro e um tornar-se o mesmo. O eterno retorno é o movimento de tornar-se o mesmo infinitamente, mas o outro movimento de tornar-se o outro opera concomitantemente. Aquilo que se torna se repete. É como se, numa variabilidade infinita, cada variação posterior se assemelhasse à anterior.

Revir é o ser disto que devém, revir é o ser do devir ele mesmo, o ser que se afirma do devir. O eterno retorno é o movimento de revir, e é esse movimento de repetir-se de uma variação que constitui o ser, e é este repetir-se que é unívoco. O eterno retorno é o ser do devir enquanto tal. Há devir e quando um movimento seguinte é igual ao movimento anterior temos repetição, temos "ser". É este retornar-se, repetir-se que pode ser afirmado de tudo o que é dito ser. Mas não o conteúdo da repetição, este é equívoco e é sempre diferença em relação a outro repetir-se: "Revir, é o ser do que devém" (DELEUZE, 1998, p.54). Ora, como diz Deleuze, não é o ser que revém, mas o revir ele mesmo constitui ser enquanto ele se afirma do devir e do que passa: "Não é o um que revém, mas o revir ele mesmo é o um que se afirma do diverso ou do múltiplo. Em outros termos, a identidade no eterno retorno não designa a natureza do que revém, mas ao contrário o fato de revir para o que difere" (DELEUZE, 1998, p.55). Por isso, com Nietzsche, se a identidade ou a unidade são segundas e não fundantes, mas resultantes, Deleuze pode pensar numa lógica do múltiplo por si, porque o ser é produzido pelo 
devir, pensado como diferença consigo, o auto-diferir de si com o eterno retorno torna-se reprodução do devir.

Mas será com Bergson, a partir do conceito de multiplicidade virtual, que Deleuze vai conceber uma lógica do múltiplo que se articula por si e em si. Se, com Nietzsche, Deleuze encontra a justificativa para pensar a relação do múltiplo por si e em si, com Bergson, ele conceberá o múltiplo como se articulando em si, sem a ideia de exterioridade à natureza e sem eminência. Será na relação do múltiplo em si que vai aparecer a significação sem a referência a uma unidade de sentido tomado como tipo, como eminente ou transcendente. Com a filosofia de Bergson Deleuze aprende, a partir da distinção entre multiplicidade virtual e multiplicidade atual, a necessidade de uma lógica do múltiplo nele mesmo. Se não há forma superior de ser, será a relação dos termos em relação que produzirá a significação. A natureza será multiplicidade de multiplicidades e a filosofia sua teoria. A leitura de Bergson faz Deleuze conceber a relação interna do múltiplo em si e por si mesmo. Mas será com Nietzsche que Deleuze conceberá a idéia de que a unidade é sempre segunda. Com Nietzsche o que é afirmado univocamente é afirmado da diferença, do múltiplo.

A analogia de proporção surgia a partir da necessidade de uma medida aplicável a todos os entes, uma medida comum capaz de hierarquizar os entes. Havia a distinção de dois tipos de relação analógica, a idéia de que o ser se diz em vários sentidos, analogia de proporção (com um termo de referência na série) e analogia de proporcionalidade (que é relação de relações a partir de uma relação de relações típica).A analogia de proporção implicava uma distribuição do sentido de ser nas formas determináveis que se distinguiam e variavam o sentido, mas que mesmo assim mantinham uma relação proporcional ao termo tomado como tipo e que portava a unidade de significação. Deleuze diz, então, que "a repetição é a única ontologia realizada, quer dizer, a univocidade do ser" (DELEUZE, 1968, p.387). Há formas de ser diferentes, mas essas diferenças não acarretam pluralidade de sentidos de ser. Mas também não são diferenças de grau. Há pluralidade das formas, mas univocidade ontológica. Podemos arriscar a dizer que a univocidade do ser é uma univocidade formal, o ser se diz em um único sentido, mas aquilo ao qual ele se diz é sempre diferente ou múltiplo. O conteúdo daquilo ao 
qual afirmamos ser o ser é sempre múltiplo, mas se é dito ser é unívoco porque é um repetir-se. A diferença sempre se expressa num repetir-se. Sem um "repetir-se" não há o aparecer de, mas variabilidade infinita. Repetir-se é, então, consistir-se.

A univocidade nietzschiana é vista por Deleuze como mais radical do que a univocidade spinoziana, o ser se diz em um só e mesmo sentido como eterno retorno, mas se diz das diferenças. Quanto ao conteúdo, há multiplicidade, mas quanto à forma há univocidade. "O ser se diz de todos os modos em um só e mesmo sentido, mas ele se diz ainda do que difere e se diz da diferença mesma...” (DELEUZE, 1968, p.387). Concilia-se assim univocidade e diferença individuante (que é não-modal quantitativa):

"A univocidade significa: o que é unívoco, é o ser ele mesmo, o que é equívoco é isto ao qual ele é afirmado... o ser se diz em um só e mesmo sentido de todas as suas formas... há uma só e mesma voz para todo o múltiplo às mil vozes, um só e mesmo Oceano para todas as gotas, um só e mesmo clamor do ser para todos os entes" (DELEUZE, 1968, p.387).

No início do capítulo dois de Que é a filosofia? lemos:

A filosofia é um construtivismo, e o construtivismo tem dois aspectos complementares que diferem em natureza: criar conceitos e traçar um plano. Os conceitos são como as vagas múltiplas que sobem e descem, mas o plano de imanência é a vaga única que os enrola e desenrola (DELEUZE, 1991, p.38).

Sem entrar na discussão acerca dessa ideia de construtivismo em filosofia, pela qual se relacionam criação de conceitos e instauração de plano, podemos perceber que Deleuze determina melhor nesta segunda passagem de Que é a filosofia? o que entende por "uma só voz que clama o ser" ou a ideia de um só oceano para todas as gotas múltiplas, trata-se do plano de imanência. Comparando o final de Diferença e Repetição com essa passagem de Que é a filosofia? podemos afirmar que o plano é o oceano que contém todas as gotas, o plano é o que envolve em si o múltiplo. A ideia de plano de imanência é, então, a resposta deleuziana ao problema da univocidade. 


\section{A ideia de plano de imanência}

Os três momentos da univocidade que esboçamos mostraram: 1) a não existência de uma forma superior e absoluta de ser, crítica da analogia de proporção e da eminência; 2) a não existência de uma exterioridade radical à natureza, imanência; 3) a existência, justificada, de uma lógica interna ao múltiplo. Mas como pensar uma lógica interna ao múltiplo ou uma teoria das multiplicidades a lado da exigência de uma filosofia que não aceita a eminência nem a analogia de proporção? Como pensar uma teoria das multiplicidades ao lado da exigência de univocidade dos sentidos do ser?

Acreditamos que a constituição da ideia de plano de imanência, e de sua relação com o conceito de multiplicidade virtual, é feita por Deleuze para tentar responder a estas perguntas. "Plano de imanência" e "multiplicidade virtual" são a resposta deleuziana ao desafio de se pensar a univocidade relacionando-a a uma lógica do múltiplo enquanto tal.

Deleuze diz que é a distinção entre dois tipos de multiplicidade a grande inovação bergsoniana. Bergson substitui o problema da relação Um e Múltiplo pela diferença entre as duas multiplicidades. Ele diz também que o múltiplo, antes adjetivo, no sentido de que era atribuído a algo tomado como unidade, tornou-se substantivo (DELEUZE, 1996, p.171). Dizer que o termo "multiplicidade" não designa um adjetivo, mas um substantivo, significa que ser múltiplo não é a propriedade de alguma coisa, mas a própria coisa: tudo é multiplicidade. As multiplicidades serão as tais gotas de que Deleuze fala tanto em Diferença e Repetição quanto em Que é a filosofia, e o plano, o oceano unívoco que as engloba. Tanto que antes de falar sobre o plano como o oceano ou a vaga única em Que é a filosofia, Deleuze o relaciona aos conceitos: criar conceitos e instaurar um plano é o construtivismo em filosofia, mas o conceito para Deleuze é uma multiplicidade. Deste modo, quando, neste texto, fala em vaga única que englobas as gotas, ele está fazendo referência à relação plano/multiplicidades, e ao usar em Diferença e Repetição os mesmos termos dizendo que o ser possui uma só voz como o oceano que engloba as "gotas múltiplas" está querendo dizer que o ser unívoco de neste texto é o "plano de imanência" de Que é filosofia. A filosofia de Deleuze substitui o problema Um/múltiplo pelo problema da relação Plano de imanência/multiplicidades. 
De um lado temos a ideia de plano que representa a compreensão deleuziana da univocidade, de outro, a sua concepção de que as coisas são multiplicidades. Como relacionar estes dois pensamentos? Só podemos compreender esta relação entre univocidade e lógica das multiplicidades ao relacionarmos plano e multiplicidades. $\mathrm{O}$ que estamos querendo mostrar é que a filosofia de Deleuze não pensa mais em termos de Um/ múltiplo, mas em termos de plano e multiplicidades, esse é seu último pensamento formulado. Sua filosofia é uma precisão desse problema, sua filosofia é a explicitação da relação plano de imanência / multiplicidades.

Deleuze afirma que:

A trindade complicação-explicação-implicação dá conta do conjunto do sistema, quer dizer do caos que contém tudo, das séries divergentes que saem e entram, do diferenciante que os relaciona umas às outras. Cada série se explica e se desenvolve, mas nas diferenças, com as outras séries que ela implica e que a implicam, que ela envolve e que a envolvem, no caos que complica tudo (DELEUZE, 1997, p.161-162).

Antes de comentar esta passagem precisamos de outra formulação: Chamamos complicação o estado do caos que retém e compreende todas as séries intensivas atuais que correspondem às séries ideais, que as encarnam afirmando sua divergência. Assim, o caos recolhe em si o ser dos problemas, e dá a todos os sistemas e todos os campos que se formam nele o valor persistente do problemático. Chamamos implicação o estado das séries intensivas, enquanto elas comunicam por suas diferenças e ressonando formam campos de individuação. 'Implicado' cada uma o é pelas outras, que ela implica por sua vez; elas constituem os 'envolventes' e os 'envolvidas', os 'resolventes' e os 'resolvidas' do sistema. Chamamos enfim explicação o estado das qualidades e extensões que vêm recobrir e desenvolver o sistema, entre as séries de base: aí se desenham as diferenciações, as integrações que definem o conjunto da solução final (DELEUZE, 1969, p.359).

Com estas duas passagens há o começo da determinação da relação entre plano de imanência e multiplicidades qualitativas. $O$ caos se refere à noção de complicação, o plano à noção de perplicação, as multiplicidades virtuais à de implicação, e a de multiplicidades atuais à de explicação. 
Comecemos pela noção de implicação. Deleuze fala em séries implicadas, implicantes, de séries que se explicam e se desenvolvem na diferença com outras séries. Estas séries se implicam, coexistem e se relacionam entre si no plano que as consiste e articula. Elas são simultâneas, contemporâneas, coexistentes e interpenetrantes num plano que as engloba. Quando são explicitadas podemos falar em séries, uma após a outra, podemos falar em sucessão, em analogia de proporção onde uma série é derivada e outra modelo ou cópia. Mas no caos elas estão misturadas. A rigor só se pode falar em multiplicidades quando cortamos e selecionamos o caos a partir de um plano de imanência. Nossa argumentação começa com a noção de implicação, mas ao mesmo tempo introduzimos a noção de complicação. No caos, não há séries, não há organização de séries. Já o plano é o complexo de coexistência das multiplicidades rizomáticas, que Diferença e Repetição ainda chama de séries.

Mas esgotemos a noção de implicação das "séries" ou multiplicidades virtuais, qualitativas. Uma multiplicidade virtual é dita implicada e implicadora ou envolvedora. Ela é implicada na multiplicidade atual secundariamente, mas primeiramente em si e em outras multiplicidades virtuais. A implicação é sua forma de ser, implica coexistência e estar em outra, penetrá-la, conectá-la e ser conectada. O que é implicado são suas variações, e o que faz implicar são diferenças. Uma diferença com outra multiplicidade faz com que essa primeira que é diferente implique um campo de variações inseparáveis num plano. Uma "série" de variações em relação, que determina suas dimensões, constitui sua diferença com outras multiplicidades que possuem outra implicação de suas variações. Mas esta multiplicidade, que implica em si relações de variações ou variações de relações, se interpenetra e é implicada em outra multiplicidade que por sua vez, constitui um campo de inseparabilidade de relações de variação entre as relações de relações. Implicação aqui significa o mesmo que consistência. As multiplicidades implicam ou consistem variações em si e consistem e implicam outras multiplicidades que consistem variações nelas mesmas: "Devemos distinguir dois tipos de multiplicidades... as multiplicidades implícitas e as explícitas, aquelas donde a métrica varia com a divisão e aquelas que portam o princípio invariável de sua métrica" (DELEUZE, 1997, p.307). As multiplicidades implícitas são as multi- 
plicidades virtuais e as explícitas as multiplicidades atuais ou quantitativas. Desenvolvamos então a noção de explicação, retomando a seguinte afirmação de Deleuze:

Devemos distinguir duas ordens de implicação, ou de degradação: uma implicação segunda, que designa o estado no qual as intensidades são envolvidas nas qualidades e no extenso que as explicam; e uma implicação primária, designando o estado no qual a intensidade é implicada nela mesma, a cada vez, envolvente e envolvida (DELEUZE, 1997, p.309).

É esta implicação segunda que tem a ver com a expressão. O caos sendo complicação de variações, o plano é a sua colocação em redes, em sistemas, em multiplicidades, consistindo e tornando inseparáveis variações em si, constituindo assim uma multiplicidade qualitativa com determinado número de dimensões, e consistindo as multiplicidades qualitativas entre si articulando-as, as multiplicidades em si mesmas sendo implicação ou consistência de variações inseparáveis são explicadas ou desdobradas em multiplicidades quantitativas. Mas, mesmo explicadas, elas estão implicitamente unidas a estas multiplicidades quantitativas.

O caos compreende, recolhe, complica as variações, por isso é variabilidade infinita. As multiplicidades são implicação em si de variações e implicação com outras multiplicidades. A explicação é atualização, desenvolvimento das relações de variação das relações num plano de referência. A explicação das multiplicidades virtuais é a passagem do virtual ao atual, é uma diferenciação. A explicação é a formação de estados de coisas e de suas relações. E a perplicação é a colocação em rede através do plano de imanência.

Um "sistema" plano/multiplicidades é distinto de outro, ou mais complexo, porque apresenta valores de implicação diferentes de outro. Esses valores de implicação identificam o número de dimensões que um plano comporta. Essas dimensões são a rede de relações de relações, de variação de relações e da relação de variação das relações de relações que um plano consiste: "É a presença desses valores que permite julgar da complexidade ou da complicação de um sistema e que determina as características do sistema" (DELEUZE, 1997, p.329). Estes valores de implicação são os centros de envolvimento ou se quisermos centros de 
consistência que são as multiplicidades. Esses valores de implicação são valores ou índices de endo-consistência.

Uma multiplicidade virtual é assim chamada porque é constituída pela coexistência virtual de relações entre elementos, que são relações, também, de determinado tipo. Essa coexistência implica um plano que consiste relações entre variações de relações. Uma multiplicidade é chamada virtual porque "virtual" designa um "modo" de ser específico. Quando se diz que os elementos de uma multiplicidade qualitativa são virtuais, isso quer dizer que esses elementos são ideais, sem figura nem função, mas reciprocamente determináveis em uma rede de relações de relações. Cada "ente" sendo uma relação de relações é uma singularidade: "Uma singularidade é o ponto de partida de uma série que se prolonga sobre todos os pontos ordinários do sistema até a vizinhança de uma outra singularidade, esta aqui engendra uma outra série que ou converge ou diverge com a primeira" (DELEUZE, 1997, p.357). Uma singularidade é um nó de relações. O estabelecimento de um "nó" é função do plano que estabelece um índice, um limiar de variação de relações, e a distribuição de singularidades (nós de relações). Uma multiplicidade é, assim, uma "totalidade" de variações internas que comporta níveis.

Para chamarmos uma multiplicidade de virtual (e, assim determinar qual seria o "modo" de ser do virtual):

$1^{\circ}$ é preciso que os elementos da multiplicidade não tenham nem forma sensível nem significação conceitual, nem função assinalável. Eles não têm mesmo existência atual e são inseparáveis de um potencial ou de uma virtualidade. É dessa maneira que não implicam nenhuma identidade prévia...; $2^{\circ}$ é preciso que estes elementos sejam determinados, mas reciprocamente, por relações recíprocas, que não deixam subsistir nenhuma independência (DELEUZE, 1997, p.237).

Este caráter de relações recíprocas intrínsecas de uma multiplicidade constitui um "dentro" ou, numa outra terminologia, uma endoconsistência. Mas comentemos primeiramente a segunda condição. Numa multiplicidade qualitativa seus elementos são relações de relações em variação em certo limiar e estas relações se tornam inseparáveis entre si em um plano que as constitui. A consistência das relações é estabelecida pelo plano, o que é chamado de crivo em relação ao caos - variabili- 
dade infinita onde esboçado algo, ele logo esvanece. É sobre essa endoconsistência que trata a segunda condição de identificação de uma multiplicidade virtual.

Deleuze diz: "O virtual não se opõe ao real, mas somente ao atual. $\mathrm{O}$ virtual possui uma plena realidade, enquanto virtual... o virtual deve mesmo ser definido como uma estrita parte do objeto real, como se o objeto tivesse uma de suas partes no virtual..." (DELEUZE, 1997, p.269). Todo "ente" possui uma parte atual e outra virtual, é multiplicidade virtual e atual. Deleuze afirma também que: "Toda multiplicidade implica elementos atuais e elementos virtuais. Não há objeto puramente atual. Todo atual se envolve de uma névoa de imagens virtuais" (DELEUZE, 1996, p.179). O que significa "virtual” aqui? Ele explica: "Os elementos são ditos virtuais quando sua emissão e absorção, sua criação e destruição são feitas em um tempo menor que o mínimo de tempo contínuo pensável, e que tal brevidade os mantém desde então sob um princípio de incerteza e indeterminação" (DELEUZE, 1996, p.179). O que caracteriza um "virtual" é a sua variação numa velocidade infinita, a sua inconsistência. Se uma multiplicidade é dita virtual é porque seus elementos (relações de relações) estão em variação, mas não infinitamente porque consistidas em plano, mas mesmo assim elas mantêm um limiar de variação indefinível. Essa variação possuindo um caráter de velocidade infinita é chamada de virtual. O plano é a consistência das relações, ou a inseparabilidade delas e de suas variações num limiar sempre crescente. $\mathrm{O}$ plano não estabelece uma desaceleração da variação, mas compõe sua velocidade com outras variações. É esse caráter de velocidade infinita de variações que caracteriza o virtual. O plano estabelece uma composição de velocidade das variações, o que permite relacionar uma variação a outra num limiar, mas não eliminar o caráter de esboço e da velocidade de variação infinita das relações. Ao afirma que todo objeto tem uma dimensão virtual, Deleuze quer dizer que todo objeto possui um campo de variação de suas relações, ou é um campo de variação de relações. Somos termos de relações (multiplicidade atual) e relações de relações em variação, mas inseparáveis umas das outras (multiplicidade virtual) num plano, que estabelece a relação entre as multiplicidades de dimensões diferentes e estabelece "numa" multiplicidade sua consistência. Uma multiplicidade/ plano é um valor de variação. O plano é a composição de 
uma relação entre índices de variações: “O plano de imanência compreende, a um só tempo, o virtual e sua atualização, sem que possa haver um limite assinalável entre os dois... o atual e o virtual coexistem" (DELEUZE, 1996, p.180).

$\mathrm{O}$ virtual qualifica, então, um conjunto de elementos coligados por conexões intrínsecas, que denominaríamos redes, estabelecidas por um plano de composição imanente, e estas conexões implicam um campo de variação, um limiar de variação, específicos, também estabelecidos por um plano de composição imanente. Um campo de conexões de relações de relações em um determinado valor de variação, este é o conceito de virtual. $\mathrm{O}$ atual pode ser definido como um conjunto de elementos discretos unidos por uma propriedade comum estabelecida pelo plano de composição transcendente. As relações entre elementos designam o "atual", relações entre relações designam o "virtual". No atual os termos tem primado sobre as relações. No virtual as relações tem primado em relação aos termos que são pensados como nós de rede, de relações. As multiplicidades atuais são divisíveis sem que esta operação de divisão mude a natureza da multiplicidade, são, por exemplo, as multiplicidades numéricas ou de grandeza onde, mesmo antes de operar a divisão, podemos conhecer de antemão o resultado. A lei da operação é uma função entre variáveis e constantes. Ao contrário, as multiplicidades virtuais mudam de natureza quando operamos uma divisão. A lei de divisão e o princípio métrico não são determináveis a priori. Se elas se dividem, elas se diferenciam, mudam sua natureza, porque elas envolvem relações de relações. A explicitação das relações é o estabelecimento de determinada conexão entre elas e, portanto, de uma diferenciação. Numa multiplicidade atual, o todo contém elementos a título de partes, que são diferenças numéricas ou de graus e a multiplicidade contém uma escala que hierarquiza e reporta as diferenças. Nas multiplicidades virtuais o todo não contém suas partes a título de elementos, mas de constituintes. E seus constituintes estão implicados uns nos outros, o que faz com que a diferenciação entre eles se faça a partir de uma métrica indeterminada ou inexata. Seus constituintes são diferenças de natureza relacionadas entre si por um plano de consistência. Cada termo de uma multiplicidade virtual é uma rede de relações composta por um plano imanente. 
O ser unívoco em Deleuze é dito virtual e atual. O virtual é a natureza naturante e o atual a natureza naturada. A diferença em relação a Bruno é que, se para Bruno a natureza naturante designa a totalidade, em Deleuze, pela sua "passagem" spinozista e nietzschiana, a natureza naturante e a natureza naturada designam tudo o que pode ser dito ser.

\section{Conclusão}

Em Mil Platôs Deleuze afirma que:

... cada indivíduo é uma multiplicidade infinita, e a Natureza inteira uma multiplicidade de multiplicidades perfeitamente individuada. $\mathrm{O}$ plano de consistência da Natureza é como uma imensa Máquina abstrata, no entanto real e individual, cujas peças são os agenciamentos ou os indivíduos diversos que agrupam, cada um, uma infinidade de partículas sob uma infinidade de relações mais ou menos compostas (DELEUZE, 1980, p.311).

A natureza é uma multiplicidade de multiplicidades e um plano de consistência. Ela é o meio unívoco em que tudo existe e se relaciona. A natureza é um plano de consistência das multiplicidades e esse plano é unívoco. Deleuze explicita:

Há, portanto, unidade de um plano da natureza, que vale tanto para os inanimados, quanto para os animados, para os artificiais e os naturais. Esse plano nada tem a ver com uma forma ou uma figura, nem com um desenho ou uma função. Sua unidade não tem nada a ver com a de um fundamento escondido nas profundezas das coisas, nem de um fim ou de um projeto no espírito de Deus (DELEUZE, 1980, p.311).

A unidade do plano de imanência é expressa no mundo e não uma dimensão a mais em relação à natureza, não é exterior a ela como o seria uma causa final ou projeto. O plano não é causa final, uma finalidade seria sempre algo a mais em relação ao que se organiza. Deleuze diz que: "o plano de imanência ou de univocidade se opõe à analogia” (DELEUZE, 1980, p.311). Esta frase confirma, então, nossa hipótese de que a idéia de plano de imanência é construída em relação ao debate histórico entre 
analogia de proporção, eminência e univocidade e, junto com o conceito de multiplicidade, funda uma vigorosa filosofia da imanência.

\section{Referências bibliográficas}

DELEUZE, G.1997. Différence et répetition. Paris: PUF.

1998. Nieztsche et la philosophie. 2ème. ed. Paris:

Quadrige/ PUF.

1968. Spinoza et le problème de l'expression. Paris: Éditions de Minuit.

DELEUZE, G.; PARNET, C. 1996. Dialogues. Paris: Flammarion.

DELEUZE, G.; GUATTARI, Félix. 1991. Qu'est-ce que la philosophie? Paris: Éditions de Minuit.

1980. Mille Plateaux: Capitalisme et

Schizophrénie 2. Paris: Éditions de Minuit. 